\title{
To Build or Not To Build: Normative and Positive Theories of Public-Private Partnerships*
}

\author{
David Martimort ${ }^{\dagger}$ and Jerome Pouyet P $^{\ddagger}$
}

September 29, 2006

\begin{abstract}
This paper analyzes whether the two tasks of building infrastructures which are socially useful in providing public services and managing these assets should be bundled or not. When performance contracts can be written, both tasks should be performed altogether by the same firm if a better design of the infrastructure helps also to save on operating costs. Otherwise, tasks should be kept apart and undertaken by different units. In incomplete contracting environments we isolate conditions under which either the traditional form of public provision of services or the more fashionable public-private partnership emerges optimally. The latter dominates when there is a positive externality and the private benefits from owning assets are small enough. Finally, we take a political economy perspective and study how incentive schemes are modified under the threat of capture of the decision-makers. Much of the gains from bundling may be lost in this case.
\end{abstract}

Keywords: Public-Private Partnership, Bundling/Unbundling, Agency Costs, Capture.

JEL Codes: H11.

\section{Introduction}

One of the most intriguing issues in modern industrial organization consists of delineating the optimal division of labor between the public and the private spheres. In this respect, the recent privatization wave which took place over the eighties and nineties in most industrial countries and which was also advocated by international agencies for developing countries certainly testifies that this question is at the heart of most major reforms. Even though defenders of full privatization schemes can still be found nowadays in the most liberal spheres, an unequivocal commitment to privatization is often viewed as an excessive

\footnotetext{
${ }^{*}$ We are grateful to several members of Veolia Institute for helpful discussions which have motivated this research. We also thank Elisabetta Iossa, Marc Ivaldi, Markus Ksoll, Jan-Eric Nilsson, Patrick Rey, Eric Strobl, Jean Tirole, and, especially, Bernard Caillaud and two referees for helpful comments on a previous version.

${ }^{\dagger}$ University of Toulouse (IDEI, GREMAQ) and Institut Universitaire de France. Address: IDEI, Manufacture des Tabacs, Bât. F, 21 Allée de Brienne, 31000 Toulouse, France. Phone: +33(0)561128614. Fax: +33(0)561128637. E-mail: martimor@cict.fr.

${ }^{\ddagger}$ Ecole Polytechnique and University of Toulouse (IDEI). Address: Department of Economics, Ecole Polytechnique, 91128 Palaiseau Cedex, France. Phone: +33(0)169332646. Fax: +33(0)169333858. Email: jerome.pouyet@polytechnique.edu
} 
response to the inefficiency of the public sector (if any) even when privatization is accompanied by a convenient regulatory environment. Most scholars and public decision-makers advocate thus for a more pragmatic approach which consists of promoting efficient (or at least as efficient as possible) partnerships between the public and the private sectors for the provision of major services and public goods. ${ }^{1}$ Only tasks where the private sector has a comparative advantage should thus really be delegated to the private sphere.

To understand the optimal pattern of delegation it is useful to keep in mind that most public services (like water management, waste disposal services, sanitation, public transportation, prison management) involve a complex array of tasks. Those activities necessitate indeed, first, to build infrastructures and, second, to operate these assets as efficiently as possible. Delegation to the private sector thus takes place de facto in a multi-task environment. ${ }^{2}$

The traditional form of public procurement used in most industrial countries has so far relied on some kind of unbundling of these tasks. First, a government designs the characteristics and quality attributes of the project. Second, the government chooses a private builder to build assets but retains ownership. Finally, the government chooses an operator, who may be either public or private, to manage these assets and provide the service. More recently, several initiatives around the world ${ }^{3}$ and various legal reforms ${ }^{4}$ have proposed an alternative form of procurement, the so-called Public-Private Partnerships (PPPs henceforth). With this procurement mode the government takes a more minimalist stance: it only chooses a private consortium which is in charge of both designing the quality attributes of the infrastructure, building these assets and, finally, managing them as efficiently as possible. Compared with the more traditional form of procurement, the PPP alternative is thus characterized by two important features. First, the two tasks of building and managing assets are now bundled. Second, the ownership pattern is also quite different.

Taking first a normative point of view, the first objective of this paper is to understand why and under which circumstances those two alternative forms of procurement are optimal. Of course, this issue is really only relevant in a framework where delegation of tasks to the private sector also comes with some agency problem. ${ }^{5}$ To make the analysis interesting we will thus envision the case where efforts in building and managing assets are non-verifiable and delegation comes with moral hazard. We then ask whether or not agency costs exhibit some kind of economies of scope when tasks are bundled. The analysis shows that ownership and its impact on incentives is not the key to understanding the optimal form of procurement. Instead, the key reason for bundling is to be found in technology and in the impact of a good design on operating costs, not on the ownership issue which is only secondary. This result is quite robust to the space of compensation

\footnotetext{
${ }^{1}$ See the 1998 United Nations Development Programme.

${ }^{2}$ See Holmström and Milgrom (1991) (moral hazard) and Laffont and Tirole (1993, Chapter 3) (adverse selection) for general analysis of the multi-task problem.

${ }^{3}$ Berger (1985) traces the references to partnerships between the public and the private sectors in the U.S. to the Carter administration and its willingness to include private actors in the development of urban projects in areas of very costly public funds and huge public deficits. Daniels and Trebilcock (2002) offer a nice overview of some issues raised by public-private partnerships in Canada.

${ }^{4}$ See the June 2004 text prepared by the Raffarin government in France, for instance.

${ }^{5}$ Otherwise the first-best could be achieved with simple forcing contracts, thereby making the organizational issue of whether to bundle the two tasks irrelevant.
} 
schemes that can be used by the local government to delegate the services and to the exact organizational form taken by the merger of two firms when tasks are bundled.

Two cases are a priori feasible and are documented by practitioners. First, a better design of the infrastructure may help to save on operating costs, the case of a positive externality. The prison sector serves as a prime example because the design of a prison may significantly affect the cost of implementing a given security level. ${ }^{6}$ Second, a better design may also require learning new procedures for managing assets and thus increase operating costs, the case of a negative externality. As an illustration, the report made by the French Cour des Comptes following the Roissy Airport Terminal E2 crash argued that an important issue was that Aéroport de Paris cumulated several 'hats' as an owner of the infrastructure, a designer and a builder. It argued that this bundling of tasks induced a sacrifice in terms of the quality of the infrastructure.

With a positive externality both tasks should be performed by the same firm which is better able to internalize the impact that a better infrastructure design has on operating costs. Intuitively, under moral hazard, there is a trade-off between providing incentives to the builder to improve the quality of the infrastructure and giving him insurance against adverse shocks on the realized quality. This trade-off calls for reducing the power of incentives so that the builder exerts less than the first-best effort. This decreased quality of the assets may excessively increase the operating costs and thus exerts a negative externality on the operator if building and managing assets are unbundled. The builder and the operator should thus be merged into a single entity. The optimal organizational form exhibits thus an important feature found in public-private partnerships. For a negative externality, the two tasks should be split because solving the agency problem on one task exacerbates the incentive problem on the other. This is reminiscent of the tasks separation occurring under standard procurement practices.

The previous argument behind the optimal organizational form is thus unrelated to the ownership issue. In practice, performance contracts are, however, not always feasible and ownership matters. For instance, the quality attributes of an infrastructure may be hard to specify in advance so that complete contracting with a builder may be difficult or even impossible to write. Ownership provides then incentives to improve quality. The allocation of ownership can thus be viewed as a specific form of contracts with imperfect incentives alignment and imperfect insurance properties. ${ }^{7}$

When incentives for building can only be provided by allocating ownership, the decision whether to bundle the two tasks may help to improve the quality-enhancing effort. For instance, when the private owner does not have enough private incentives to improve the quality of the assets, making him also responsible for the management of these assets fosters incentives in the case of a positive externality. In such incomplete contracting environment the modern form of public-private partnerships emerges when private owners have rather weak incentives to enhance assets quality compared with what would be socially optimal. On the other hand, the traditional form of procurement emerges when the externality is negative and uncertainty on the realized quality of the assets is too large to let private owners bear such risks.

\footnotetext{
${ }^{6}$ See Schneider (2000).

${ }^{7}$ Because assets are privately owned, the owner may not internalize the full social value of her investment in enhancing the quality of the infrastructure.
} 
Although the normative arguments above have certainly some appeal, they do not explain the fierce opposition to the modern form of public-private partnerships that is sometimes found among practitioners and political decision-makers. Opponents often argue that this organizational form may increase the scope for capture of the decisionmaker so that the possible efficiency gains from bundling may be offset by influence costs. ${ }^{8}$ In fact, as a decision-maker may find both bundling and unbundling optimal depending on the kind of externality between tasks, he may exert his discretion to favor the industry by this organizational choice. To analyze these issues we must significantly extend our model. First, the decision-maker must have private information on the sign of externality so that manipulations of his decision can be made at the expense of the general public. Second, the operator willing to integrate backwards into infrastructure building must also obtain some rent from doing so and, here again, some sort of private information is needed. ${ }^{9}$ Now, the political economy drawback from the bundling decision becomes clearer. Because bundling is called for in the case of a positive externality, it raises also incentives to improve operating costs. Under adverse selection, this is a source of a greater information rent. ${ }^{10}$ Even when the externality is negative and unbundling is socially optimal, the operator has an incentive to bribe a (non-benevolent) decision-maker to integrate backwards and also build the infrastructure by herself. When the social cost of such collusion is taken into account, bundling may not be as attractive.

Let us now turn to a brief review of the literature. Two papers address issues close to ours: Bennett and Iossa (2002) and Hart (2003). Both papers lie in the realm of the property rights literature à la Grossman and Hart (1986): Inefficiencies in assets qualityenhancing and cost-reducing efforts stem from the hold-up problem that arises when no contract can be written and only ex post negotiation between the government and the operator and/or builder is feasible. Although ex post efficient, this negotiation generates payoffs which depend on the threat points defined by the ownership structure. ${ }^{11}$ By a reasoning close to the one we will make in our more complete contracting environment, a positive externality somewhat weakens the hold-up problem on both tasks and calls thus for integration. Even though they are similar in spirit, our findings should nevertheless be distinguished and contrasted. First, even though, we are quite sympathetic to the idea that the quality of assets may be hard to describe in advance, so that complete contracts with a builder may be difficult to enforce, ${ }^{12}$ one may be more skeptical of the use of this paradigm when it comes to analyzing the relationship between the government and the operator. Operating costs are readily observable and often used in practice to contract for service provision. This suggests that the role of ownership might have been overemphasized so far. More basic agency problems may actually explain much of the organizational forms which emerge, even though the distortions due to ownership allocations can be superimposed. Second, because the property rights approach de-emphasizes informational

\footnotetext{
${ }^{8}$ In Libération dated June $21^{\text {th }}$ 2004, Arnaud Montebourg, an impetuous young leader of the French socialist party argued that PPPs had a "caractère opaque et corrupteur" (a feature of opacity and corruption).

${ }^{9}$ The pure moral hazard model analyzed in the first part of the paper does not generate any rent to the builder and operator.

${ }^{10}$ See Laffont and Tirole (1993, Chapter 1) for instance.

${ }^{11}$ See also Hart, Shleifer and Vishny (1997) for such an analysis.

${ }^{12}$ Indeed we use this idea in Section 6 below.
} 
issues, it cannot endogenize the stake for capture and address the political economy issues which are crucial to getting any positive theory of public-private partnerships. This is where a second important insight available within our framework lies.

This paper belongs also to a broader theoretical literature which investigates task assignments in organizations in the presence of agency problems. In pure moral hazard environments, Holmström and Milgrom (1991) showed that incentives in one task may destroy incentives in another when tasks are substitutes in the agent's cost function; a result which suggests that tasks should be split when there is a negative production externality. Although the result that complementary tasks should be bundled altogether can also be found in Holmström and Milgrom (1990), Macho-Stadler and Perez-Castrillo (1993), Itoh (1994), and Ramakrishnan and Thakor (1991) under various forms, the specific context of public-private partnerships and, most specifically, the sequentiality of tasks imposes some specific assumptions on contracts under unbundling and a more thorough discussion of what is cooperation between separated entities than what the existing literature provides. ${ }^{13}$ In particular, we will distinguish below between the case where the two tasks are bundled altogether and performed by the same agent, keeping her risk tolerance as given, and the case of a consortium where the two tasks are jointly performed. The first of these organizational choices focuses on the incentive effect of bundling tasks, whereas the second one introduces risk-sharing benefits which are already well-known from the literature. ${ }^{14}$ From a methodological perspective, when considering the bundling of tasks, our analysis allows one to clearly disentangle the impact on incentives from the benefit associated with improved risk-sharing. Schmitz (2005) investigates a sequential moral hazard model with limited liability as the source of the agency problem, no production externality but with the added twist that the outcome of the first project affects the cost of incentives on the second one. Finally, in pure adverse selection frameworks, Baron and Besanko (1992, 1999), Dana (1993), Gilbert and Riordan (1995), Laffont and Martimort (1998), Mc Afee and Mc Millan (1995), Mookherjee and Tsumagari (2004), and Dequiedt and Martimort (2004) have also discussed whether bundling tasks and having a single agent privately informed on cost parameters related to each task dominates unbundling when tasks are perfect complements.

The paper is organized as follows. Section 2 presents the model. Section 3 addresses the respective optimality of bundling and unbundling tasks when both the builder and the operator receive a compensation scheme which depends only on their own performance. This means that, although the operator's cost may later on reveal some information on the builder's effort, costs are not used to compensate the builder. Under bundling the two tasks are undertaken by a unique firm, the merger of the builder, and the operator. Section 4 generalizes our findings to the case where the cost realizations can also be used to compensate the builder and delayed payments are feasible. Section 5 enters in more detail into the process of merger formation. Within a consortium two otherwise identical risk-averse firms perfectly coordinate their decisions and share risk. Again bundling is

\footnotetext{
${ }^{13}$ More generally, the impact of production externalities on the kind of incentive schemes used in multiagent contexts (most notably relative performance evaluations versus joint performance evaluations), keeping this separation between agents as given, has also been investigated in Choi (1993) and Che and Yoo (2001)

${ }^{14}$ This result is already well-known from Holmström and Milgrom (1990), Macho-Stadler and PerezCastrillo (1993), Itoh (1994), and Ramakrishnan and Thakor (1991).
} 
optimal for a positive externality but may also be so for a negative one thanks to a coinsurance motive. Section 6 tackles the ownership issue and isolates conditions under which either the more traditional form of procurement or the more novel form of publicprivate partnerships dominates. Section 7 discusses the political economy of the model. Section 8 briefly concludes by presenting alleys for further research. Proofs are relegated to an Appendix.

\section{The Model}

Consider the two tasks of building a key infrastructure and managing these assets: Should these tasks be bundled and performed by the same firm or by two different entities (sometimes referred to as the agents) contracting independently with a common local government (the principal). ${ }^{15}$ Let the builder of this infrastructure (resp. the operator) be denoted by $\mathcal{B}$ (resp. $\mathcal{O}$ ). A merger of those two firms is denoted accordingly as $\mathcal{B}-\mathcal{O}$.

Both firms are symmetric and have the same CARA utility function with risk-aversion $r .{ }^{16} \mathrm{~A}$ merger $\mathcal{B}-\mathcal{O}$ is also assumed to have the same degree of risk aversion. A merger corresponds thus to the case where both tasks are a priori allocated to one of the two existing firms. ${ }^{17}$

Building and managing assets are two activities which are both subject to moral hazard. Although the builder exerts a non-verifiable effort $e_{1}$ to improve the intrinsic quality of the infrastructure, only a rough quality index $\tilde{q}$ can be used for contracting purposes with:

$$
\tilde{q}=e_{1}+\tilde{\varepsilon},
$$

where $\tilde{\varepsilon}$ is a random shock which is normally distributed with zero mean and variance $\sigma_{\varepsilon}^{2} \cdot{ }^{18}$ Indeed, the intrinsic quality of an infrastructure may not be fully observable. In the case of water networks, although the quality of produced water can be tested and specified in the contract between the service provider and the municipality, it is only indicative of the effort incurred in correctly designing and building these assets. The intrinsic quality of the network (quantity of leakages, quality of the tubes, etc.) remains by large not observable. Other interpretations of our quality index include the delay in building the infrastructure or the adequacy between the agent's design of the infrastructure and the community needs.

The local government withdraws a benefit $S \times q$ (where $S>0$ ) from building an infrastructure with quality $q$. This benefit includes not only the private value pocketed by owners, but also any externality that this infrastructure may generate in terms of employment or boosting economic activity. Society also withdraws a benefit from the operations that we keep as fixed and does not need to be modeled for simplicity. The local government has all the bargaining power in designing contracts with the builder and the

\footnotetext{
${ }^{15}$ Our focus on two tasks only is made in order to capture the essence of the argument. In the real word one often has to distinguish between designing a project, getting outside financing, building the corresponding infrastructure, and managing these assets.

${ }^{16}$ The symmetry assumption is again made for simplicity only.

${ }^{17}$ Section 5 will analyze the case where the two firms remain independent entities coordinating their efforts in a consortium.

${ }^{18}$ We denote $\mathbb{E}_{x}$ the expectation operator w.r.t a random variable $x$.
} 
operator of these assets capturing thereby the ex ante competitive supply of services in the production of key public services.

The operating costs $\tilde{c}$ are observable and contractible. However, they reflect only imperfectly the operator's non-verifiable effort $e_{2}$ in reducing these costs. We postulate the following relationship:

$$
\tilde{c}=\tilde{\eta}-e_{2}-\delta e_{1},
$$

where $\tilde{\eta}$ is a random variable normally distributed with mean $\eta_{0}$ and variance $\sigma_{\eta}^{2}$.

Exerting effort $e_{i}$ on given task costs $\psi\left(e_{i}\right)=\frac{e_{i}^{2}}{2}$ to the concerned agent. ${ }^{19}$ For a merger these disutility functions are additive to avoid any systematic bias due to either economies or diseconomies of scale in the comparison of both organizational structures. For simplicity, both firms have the same exogenous reservation payoff which we normalize to zero.

Importantly, operating costs depend on the quality of the infrastructure (see equation (1)). The sign of this externality plays actually a major role in comparing organizational structures as we will show below:

- Positive externality, $\delta>0$ : Building an infrastructure of greater quality reduces operating costs. This happens when, for instance, these infrastructures facilitate operating tasks. Prisons provide an interesting example along these lines. A better design certainly makes it easier to maintain safety.

- Negative externality, $\delta<0$ : Sometimes a quite novel infrastructure design calls for innovating in some of the most operating tasks, giving up routines and learning new job processes. This certainly increases operating costs at least in the shortrun. Airports may be a case in order here. A good design in view of facilitating passengers access to terminals may nevertheless be accompanied by an increase in the costs of providing all other services required (food, shops, airplane maintenance of the tarmac, etc...). It is also a major complaint that designing, building, or maintaining existing assets are tasks which might involve large dissonance between the different teams involved; operating teams often report that the complex design of an infrastructure coming out of the design and construction team can hardly be "operated" without cost overruns. This negative externality can then be viewed as a short-cut for those dissonances which may be due to cultural backlash between different teams or to improper incentives for their members.

To avoid corner solutions at zero in the effort choices, we will assume that $\delta$ is small enough in the case of a negative externality.

Complete Information Benchmark. Suppose that efforts $e_{1}$ and $e_{2}$ are both verifiable. The principal can thus use forcing contracts to implement any such efforts pair. Then, the first-best efforts can be chosen and full insurance provided to both firms by offering them fixed-fees which cover their respective costs of effort. The first-best effort levels $\left\{e_{1}^{*}, e_{2}^{*}\right\}$ maximizes the government's expected social welfare and one finds:

$$
e_{1}^{*}=S+\delta \text { and } e_{2}^{*}=1 .^{20}
$$

\footnotetext{
${ }^{19}$ The assumption of symmetry could again be relaxed at the cost of increasing the notational burden.
} 
The first equality, for instance, just says that the expected marginal benefit of raising the quality of the infrastructure, including the extra benefits in reducing operating costs, is equal to the marginal cost of that effort.

Of course, the organizational structure is irrelevant in this complete information context. Whether bundling or unbundling is chosen yields the same first-best outcome.

\section{Organizational Forms with Restricted Schemes}

Following Holmström and Milgrom (1987), we focus on compensations which are linear in the agents' realized performances. ${ }^{21}$

Unbundling. In this environment, general linear contracts should be of the form $t(q, c)=$ $b+a q-a^{\prime} c$ for the builder and $z(q, c)=\beta-\alpha c+\alpha^{\prime} q$ for the operator. Such schemes may, however, be hard to implement in practice and even sometimes useless. Indeed, first note that there is no value in making the operator's compensation depend on the observable quality of the infrastructure. Doing so (i.e., $\alpha^{\prime} \neq 0$ ) would only increase the risk borne by the risk-averse operator without any positive incentive effect on his effort supply. The 'informativeness principle' tells us that this cannot be optimal. ${ }^{22}$

Second, the builder's payment is made just after his task has been accomplished, i.e., it takes place before operating costs are realized. General schemes $t(q, c)$ of the kind above may not be feasible when payments cannot be delayed because of, for instance, the wellknown limited commitment ability of local governments. ${ }^{23}$ Delayed payments may also be susceptible to ex post collusion and accounting manipulations between operators and local governments. For these reasons, but also because it already highlights the key costs and benefits of merging tasks, we will thus focus in this section on restricted schemes having $a^{\prime}=0$ and $\alpha^{\prime}=0$. The more complex contracting environments where delayed payments are available are analyzed in Section 4 below.

When the payment of an agent depends only on his realized performances and not on that of the other agent, $\mathcal{B}$ and $\mathcal{O}$ receive, respectively, the following linear contracts:

$$
t(q)=b+a q \text { and } z(c)=\beta-\alpha c
$$

where $b$ and $\beta$ are fixed-fee payments, whereas $a$ and $\alpha$ are piece-rate parameters.

Given the above restricted incentive schemes, the builder and the operator's marginal incentives to exert effort are given by the slopes of their respective incentive schemes:

$$
a=\psi^{\prime}\left(e_{1}\right)=e_{1} \text { and } \alpha=\psi^{\prime}\left(e_{2}\right)=e_{2} .
$$

Because compensations are based on individual performances only, the externality between the two tasks does not affect the agent's efforts. Of course, this externality still plays a

\footnotetext{
${ }^{21}$ We are not, of course, in a pure Holmström and Milgrom (1987) environment since there are two sequential tasks. We conjecture that there exists a dynamic version à la Holmström and Milgrom (1987) the limit of which would justify the use of linear contracts.

${ }^{22}$ Holmström (1979).

${ }^{23}$ This assumption on non-delayed payments is standard in the literature. See for instance Laffont and Tirole (1993, Chapter 8) for an analysis of repeated auctions of franchise contracts which also assumes that delayed payments are not feasible.
} 
role because it affects the average cost and thus how much profit is extracted from the operator through the fixed-fee $\beta$.

Assuming that the agents' profit has no weight in the social welfare function, the local government induces the agents to choose efforts $\left\{e_{1}^{u}, e_{2}^{u}\right\}$ which are less than their first-best values:

$$
e_{1}^{u}=\frac{S+\delta}{1+r \sigma_{\varepsilon}^{2}}<e_{1}^{*} \text { and } e_{2}^{u}=\frac{1}{1+r \sigma_{\eta}^{2}}<e_{2}^{*}
$$

Indeed, for each risk-averse agent there is a trade-off between providing the agent with enough incentives to exert effort on his task and reducing the risk he bears for insurance purposes. ${ }^{24}$ Because incentives expose agents to risk, the principal chooses contracts which implement too little effort, even if there is an externality that she internalizes in designing individual schemes.

Bundling. The merged entity $\mathcal{B}-\mathcal{O}$ receives now a linear scheme which depends on both its performances in building assets and operating them:

$$
t(q, c)=B+a q-\alpha c,
$$

where $B$ is an aggregate fixed-fee.

Now there is no problem in having the total payments $t(\cdot)$ being delayed until the operating costs are realized since this is the same entity which receives them. Alternatively, this payment can be decomposed into two different parts: one being offered after the realized quality has been observed, the other being delayed until costs are observed. To induce effort and participation of the merged agent only the inter-temporal transfer matters. ${ }^{25}$

The merged entity $\mathcal{B}-\mathcal{O}$ can better internalize the impact of raising the quality of the infrastructure on the operating costs. To see how, note that the merged entity maximizing the certainty equivalent of his expected profit chooses the efforts:

$$
a+\alpha \delta=e_{1} \text { and } \alpha=e_{2} .
$$

When the externality is positive, a bonus $\alpha$ on cutting costs not only helps to reduce costs by exerting more operating effort, but also improves incentives in better designing the infrastructure. The reverse happens in the case of a negative externality. Then, the principal dealing with a single agent cannot use the cost-reimbursement rule to provide incentives in two efforts which affect these costs in opposite directions.

Having determined the optimal payments and incentives under both organizational structures, we now turn to comparing bundling and unbundling.

Proposition 1. Assume that efforts are non-verifiable. Bundling is the optimal organizational structure if and only if $\delta>0$ (positive externality). Efforts are ranked as follows:

$$
e_{1}^{b}>e_{1}^{u} \text { and } e_{2}^{b}>e_{2}^{u} \Leftrightarrow \delta>0 .
$$

\footnotetext{
${ }^{24}$ See Holmström (1979).

${ }^{25}$ One can also adjust fixed-fees in each period to make this inter-temporal contract robust to the possibility that the agent leaves the relationship after having built the infrastructure.
} 
To understand this result, let us suppose that the local government decides to offer to the merger an aggregate contract that would just consist of adding up the two linear schemes offered to the builder and the operator if they had been kept apart. In terms of risk tolerance, doing so keeps unchanged the overall risk premium paid by society to induce participation of this merger. ${ }^{26}$ If there are any gains of merging tasks, they should be found on the incentives side. Under unbundling, remember that efforts are too low from a (first-best) social welfare viewpoint. ${ }^{27}$ If the local government could increase both efforts, it would unambiguously raise welfare. This is precisely what the joint offer of the contract to the merger does in the case of a positive externality. Then, the merger finds it worth to expand the effort in designing and constructing the infrastructure because it finds some additional rewards in doing so through the impact on operating costs that it fully internalizes. This is not the case with a negative externality since then the merger gets torn between his incentives to do a better design and the negative impact it has on operating costs. A better provision of incentives can be obtained by simply separating the two tasks. Then, the principal is no longer asking the agents to perform well on two conflicting tasks. Incentives are better designed by having agents being focused on only one task. Of course, this argument can be improved since the local government can actually do better by redesigning the incentives of the merger to improve even more his ability to internalize the positive externality.

This discussion raises two issues. First, what are really the gains of a merger in the case where more general contracts are already allowed under unbundling? Do we still improve effort and welfare when merging tasks and by how much? Second, what are the benefits of having separate agents sharing risks in a consortium instead of single firm in charge of both activities? Are they enough to expand the benefit of a merger beyond the case of a positive externality? We answer these questions in the next two sections.

\section{General Schemes}

To test the robustness of our results we now assume that more complex contracts can be implemented under unbundling. The contract offered to any given agent is still linear, but can now also depend on the other agent's realized action. This possibility allows one of course to achieve a weakly higher welfare under unbundling since the space of contracts is enlarged. Hence, under a negative externality, unbundling still dominates bundling. The only relevant issue is thus to compare these organizational choices assuming instead a positive externality.

Payments to the builder and the operator can now be, respectively, written as:

$$
t(q, c)=b+a q-a^{\prime} c \text { and } z(q, c)=\beta-\alpha c+\alpha^{\prime} q .
$$

Since the externality is one-sided, making the operator's payment depend on the realized

\footnotetext{
${ }^{26}$ Things are different in Section 5 below, where we model the bargaining process between two separate units to jointly decide on effort levels.

${ }^{27}$ It is well-known that the second-best level of effort in a pure moral hazard environment may not always be below its first-best level (see Laffont and Martimort (2002, Chapter 5) for instance). However, the lessons of the linear-CARA model à la Holmström and Milgrom (1987, 1991) capture the "Folklore" of the profession.
} 
quality is useless for the local government. Doing so would again only increase the risk faced by the operator, thereby leading to an increase in the risk-premium needed to ensure his participation without any incentive benefits. In the following $\alpha^{\prime}=0$ is still optimal.

By contrast, linking the builder's payment to the operator's cost (through delayed payments for instance) makes the builder internalize at least partly the one-sided externality. The builder's marginal incentives to enhance the infrastructure quality are now given by:

$$
a+a^{\prime} \delta=e_{1}
$$

The builder's effort is greater if he receives a share of the gains in cost reduction that a better design would permit.

To better understand the comparison between organizational forms, it may be useful to optimize expected social welfare first over the piece-rate parameter $a^{\prime}$ to find:

$$
a^{\prime}=\frac{\delta e_{1} \sigma_{\varepsilon}^{2}}{\sigma_{\eta}^{2}+\delta^{2} \sigma_{\varepsilon}^{2}}
$$

which is positive under a positive externality. As expected, the builder's payment decreases when costs are higher since costs provide information on the fact that the builder's effort may have been too low. Moreover, since the risk on costs can now be used to provide incentives, there is no need to let as much of the quality risk to be borne by the builder. Overall, the trade-off between incentives and insurance is relaxed and the risk-premium that society has to pay to induce the builder's participation is reduced accordingly. We show in the Appendix that the risk-premium $\frac{r \sigma_{\varepsilon}^{2} \sigma_{\eta}^{2}}{2\left(\sigma_{\eta}^{2}+\delta^{2} \sigma_{\varepsilon}^{2}\right)} e_{1}^{2}$ that must now be paid is lower than the risk-premium $\frac{r \sigma_{\varepsilon}^{2}}{2} e_{1}^{2}$ paid with restricted contracts. The fact that $\frac{\sigma_{\eta}^{2}}{\sigma_{\eta}^{2}+\delta^{2} \sigma_{\varepsilon}^{2}}<$ 1 captures therefore the informativeness gain from using costs to improve the builder's incentives. This gain is second-order in the size of the externality $\delta$. Hence, using costs to contract with the builder does not bring much in the limit of a weak positive externality.

Let us now come back to the case of bundling. The discussion after Proposition 1 shows that, by simply merging incentive schemes, the quality enhancing effort already increases in the size of the externality by first-order magnitude. Although the use of a larger class of contracts improves unbundling, it is not enough to reverse our previous findings.

Proposition 2. Assume that efforts are non-verifiable and that general contracts are available. Then there exists $\delta_{0}>0$ such that for all $\delta \in\left[0, \delta_{0}\right]$ bundling is still preferred to unbundling. Unbundling is still preferred for negative externalities.

The second part of the proposition shows that, in practice, the gains from unbundling with a negative externality can already be achieved with restricted schemes. Delayed payments to the builder do not bring much to the local government. This points to the fact that limited commitment ability on the government side does not prevent one from achieving much of the gains from splitting tasks.

\section{Consortium}

So far our modelling of a merger $\mathcal{B}-\mathcal{O}$ of the two firms has been rather crude. By assuming that both tasks were performed by a single agent, either the builder or the operator, we 
have alluded to the question of how such a coalition between the two entities might be formed in practice. In this section we precisely investigate this issue.

When considering a detailed analysis of the formation of a consortium between the two otherwise identical risk-averse agents, two problems should be kept in mind. First, by merging these two agents may be better able to share risk. A coalition improves risksharing compared to the case of a single firm. ${ }^{28}$ Second, by merging these two agents may be more or less able to observe each other's effort. The benefits of a coordinated choice of efforts might be somewhat dissipated by the internal agency problem that such a consortium may have to solve. To model a consortium of two otherwise identical riskaverse firms we will put aside this internal agency problem (efforts are mutually observable and coordination is perfect) and focus on the risk-sharing issue. ${ }^{29}$ We assume that the two firms form a joint-venture denoted by $\mathcal{J} \mathcal{V}$ which is assumed to be infinitely risk-averse. $\mathcal{J} \mathcal{V}$ 's reservation payoff is exogenously normalized to zero.

$\mathcal{J V}$ receives the aggregate net transfer $t(q, c)=B+a q-\alpha c$ from the government and then redistributes this transfer between the two individual firms $\mathcal{B}$ and $\mathcal{O}$. We denote by $t_{i}(q, c)=B_{i}+a_{i} q-\alpha_{i} c$ the share of the overall revenue which accrues to firm $i(i \in\{\mathcal{B}, \mathcal{O}\})$. Because $\mathcal{J V}$ is infinitely risk-averse, it will transfer all risk on the aggregate transfer $t(q, c)$ to the builder and the operator, so that necessarily $a_{\mathcal{B}}+a_{\mathcal{O}}=a$ and $\alpha_{\mathcal{B}}+\alpha_{\mathcal{O}}=\alpha$. Assuming that $\mathcal{J} \mathcal{V}$ has all bargaining power in designing the individual compensations of the builder and the operator, ${ }^{30} \mathcal{J V}$ maximizes the certainty equivalent of the aggregate payoff of the firms. Because they have the same risk tolerance, the firms share equally the risk of their aggregate compensation:

$$
a_{\mathcal{B}}=a_{\mathcal{O}}=\frac{a}{2} \text { and } \alpha_{\mathcal{B}}=\alpha_{\mathcal{O}}=\frac{\alpha}{2} .
$$

For a given incentive scheme offered by the government, optimal effort levels are thus still given by (4). The consortium is efficient in the sense that it perfectly internalizes the effort externality just like a merger in Section 3. However, because the two firms share risk equally, the aggregate risk-premium to be paid to induce participation of such consortium is half of what was paid in the case of the merger. Even when there is no externality, a consortium strictly dominates because it allows a better allocation of risk between two otherwise identical risk-averse firms.

Proposition 3. There exists $\delta_{0}^{\prime}>0$ such that an efficient consortium dominates unbundling for $\delta>-\delta_{0}^{\prime}$.

This result reinforces again our previous findings. Certainly, bundling must be observed for a positive externality. It also offers a justification for our earlier assumption that a merger keeps the same degree of risk-aversion as the agents. This assumption allows one in fact to focus on the incentives benefits of bundling and to disregard the issue of risk-sharing, which is another advantage already well-known in the literature. ${ }^{31}$

\footnotetext{
${ }^{28}$ This point is well-known from the collusion literature in multi-agents environments. See Varian (1989) and Itoh (1993).

${ }^{29}$ The consortium acts thus as a syndicate in the sense of Wilson (1968).

${ }^{30}$ This assumption somewhat simplifies the analysis but could easily be relaxed.

${ }^{31}$ See Holmström and Milgrom (1990), Macho-Stadler and Perez-Castrillo (1993), Itoh (1993, 1994), and Ramakrishnan and Thakor (1991).
} 


\section{Ownership and Organizational Forms}

We have so far assumed that the perceived quality of the infrastructure $q$ was observable and verifiable and could thus be used in any contract linking the government and the builder. Let us now suppose that this variable is itself non-verifiable. In this incomplete contracting environment the only feasible way of providing incentives consists of allocating ownership rights of the assets to the builder. Of course, ex post, once the quality $q$ is observed, the government and the agent can bargain over the realized gains from trade.

Whoever owns the assets enjoys a return $P \times q$ (with $P \geq 0$ ) by disposing of the assets in case the ex post negotiation breaks down. This can be viewed as the resale value of these assets. Because assets may have a greater social value than what they are worth to owners, we have $S=E+P \geq P$ where $E \geq 0$ captures the positive externality impact of the infrastructure. Several origins can be found in this discrepancy between the social and the private values of the assets. Indeed, once built, assets could be redeployed to social uses other than initially intended. Second, the infrastructure may have a positive impact on employment and local economic activities, as it has been stressed by the New Economic Geography literature.

For both the case of bundling and unbundling we may wonder what is the optimal ownership structure. Our goal in this section is thus to investigate whether the incompleteness of the contracts modelled by assuming the non-verifiability of the perceived quality $q$ affects the choice of bundling tasks or not and, if it does, in which directions these distortions should go.

Whatever the organizational structure chosen, the only feasible contracts with the builder consists now of allocating asset ownership. ${ }^{32}$ Of course, on top of this allocation, the government has to still decide of an ex ante price to be paid to the builder to induce his participation. On the other hand, contracts with the operator keep the general linear form used above. By jointly making these two different assumptions concerning the two tasks, we capture what seems to be a major feature of most real-world partnerships: the difficulty to verify quality of an infrastructure and the fact that costs instead are readily observable, verifiable, and used in cost-sharing agreements. ${ }^{33,34}$

To understand the implications of ownership, it is useful to see it as a simple contract fixing the marginal incentives to improve the infrastructure quality to either 0 under government ownership or to $P$ under builder ownership. In doing so, we thus assume that the government has all bargaining power in the ex post negotiation that takes place with the builder once the perceived quality $\tilde{q}$ is realized. With this specification in mind, it becomes easy to assess the quality-enhancing effort of the builder under both ownership structures and under both organizational forms.

Local Government Ownership. Let us first suppose that the government initially approaches a constructor, who does not keep ownership, before turning to a different operator. The builder has no incentive to design a good infrastructure whatsoever and

\footnotetext{
${ }^{32}$ We will assume that only deterministic ownership structures are relevant, which is justified when ownership can be renegotiated.

${ }^{33}$ Water management, waste disposals, transports, etc. are examples in order there. This is contrary to what is assumed in Hart, Shleifer and Vishny (1997) for instance.

${ }^{34}$ See Hart, Shleifer and Vishny (1997) and Hart (2003) for similar assumptions.
} 
thus exerts no effort, $e_{1}=0$. Under bundling, instead, and still assuming that the local government retains ownership, two cases must be distinguished depending on the sign of the externality. For a negative externality the merged entity $\mathcal{B}-\mathcal{O}$ has still no incentive to make an efficient design because this would only increase costs and reduce the only verifiable performance on which he is rewarded. Again, we have $e_{1}=0$. Social welfare is unchanged and depends only on the incentive for cost reduction.

Proposition 4. Assume that $\delta<0$. Under government ownership, bundling and unbundling yield the same outcome.

With a positive externality, the merged entity $\mathcal{B}-\mathcal{O}$ may find it instead beneficial to increase the quality of the infrastructure even though he does not own it, just because this is another way of cutting operating costs. In fact, given the positive slope $\alpha>0$ of the cost-reimbursement rule, $e_{1}$ is now raised so that $\alpha \delta=e_{1}>0$, whereas $\alpha=e_{2}$.

Since, under government ownership, the merged entity continues to bear no risk linked to the quality of the infrastructure when it is not the owner, raising effort $e_{1}$ through bundling increases welfare at least to the first order in $\delta$ when the externality is small.

Proposition 5. Assume that $\delta>0$ but small enough. Under government ownership, bundling strictly dominates unbundling.

Since explicit incentives to quality-enhancing and implicit incentives through ownership are both absent, the only way to induce quality-enhancing effort is to bundle tasks so that the builder enjoys some benefit in exerting effort $e_{1}$ through the reduction of operating costs it induces.

Builder Ownership. Under unbundling and when the builder owns the assets, his quality-enhancing effort is given by:

$$
P=e_{1}
$$

As an owner enjoying the random private returns from ownership, the builder bears also some risk and must be compensated for doing so through an ex ante risk-premium $\frac{r}{2} \sigma_{\varepsilon}^{2} P^{2}$ so that he prefers becoming an owner than taking his outside option. Of course, social welfare is still maximized by choosing the same effort $e_{2}^{u}$ as if restricted schemes where available for both tasks. The sole role of ownership is to constrain the effort on the first task to his marginal value for an owner not to the slope of the optimal incentive scheme $a^{u}$ found before.

Under bundling, the merged entity chooses a level of quality-enhancing effort which takes into account the impact on operating costs and we thus have: ${ }^{35}$

$$
P+\alpha \delta=e_{1} \text { and } e_{2}=\alpha .
$$

The cost reimbursement rule has a role which is complementary to ownership in boosting incentives in the first task.

Proposition 6. Assume that $\delta>0$ and builder ownership. If $P$ is small enough, bundling strictly dominates.

\footnotetext{
${ }^{35}$ We assume again that $\delta$ is small enough to ensure a positive effort.
} 
The intuition behind this proposition is straightforward. When ownership by itself does not give enough incentives to the builder to improve the quality of the assets, bundling improves these incentives by making the builder more eager to save also on operating costs. Of course, for bundling to dominate, one wants to make sure that ownership does not give too much incentive; otherwise bundling would be suboptimal by worsening an already suboptimal outcome.

When bundling dominates, one should note that improving incentives on the first task requires also pushing even further incentives on the second one. Builder ownership also comes with cost reimbursement rules which are closer to fixed-price contracts. Ownership and high-powered incentives go hand in hand.

Proposition 7. Assume that $\delta>0$ and that $P$ is small enough. Then bundling and builder ownership is the optimal organizational form.

As long as ownership provides enough incentives (but still not too much) to the builder to improve asset quality under bundling, the latter should not only own the assets but also manage them. Proposition 7 highlights conditions under which the most common form of public-private partnership emerges. Bundling of tasks helps to improve incentives in quality-enhancing effort when ownership of the assets alone does not suffice. ${ }^{36}$

A contrario, let us find conditions under which public ownership and separation dominates. This will correspond to the more traditional form of public procurement where two different agents are called for at the building and operating stages and government retains ownership. We already know from Proposition 4 that separation and integration are equivalent under government ownership and when the externality is negative: No incentives on quality-enhancing can be provided. The hope for unbundling to strictly dominate in this case thus vanishes. Nevertheless, we have:

Proposition 8. Assume that $\delta<0$ and that $P$ and $\sigma_{\varepsilon}^{2}$ are large enough, then public ownership and unbundling is the optimal organizational form. This is more likely as $\sigma_{\varepsilon}^{2}$ increases.

With a negative externality, the only way to incentivize effort on the first task is to give ownership to the builder. The cost of ownership is that the buyer must be compensated for the risk associated to the realized quality of these assets. When the private benefits of ownership are too high, the buyer as an owner has too much incentives and bears too much risk. Public ownership is preferred when this insurance motive is too costly, i.e., when uncertainty on the quality of these assets is too large. This is so even if public ownership destroys any incentive to improve this quality.

\section{$7 \quad$ PPPs and Capture}

So far the decision whether to bundle tasks was taken by a benevolent social welfare maximizer. Opponents to public-private partnerships have often argued that this form of procurement increases the scope for capture of non-benevolent decision-makers by private

\footnotetext{
${ }^{36}$ In case the externality generated by the project $E$ is negative, the value of the private benefits $P$ is already too high with respect to what is socially optimal and private ownership gives too much incentives to improve quality to make bundling optimal. We chose to disregard this case.
} 
interests. We now turn to this issue by introducing some political economy considerations in our model.

The bare-boned model analyzed in Section 3 already provides some hints to understanding why an operator may want to influence a policy-maker to favor bundling even though that decision may not be socially optimal. Indeed, we know from Proposition 1 that, under bundling and with a positive externality, the optimal incentive scheme offered to the operator is higher-powered than under unbundling. Formally, $\alpha^{b}=e_{2}^{b}>\alpha^{u}=e_{2}^{u}$. In the pure moral hazard model used so far, these higher-powered incentives are not the source of any rent. ${ }^{37}$ From Laffont and Tirole (1993) we know that high-powered incentives may also give excessive information rents to the operator in adverse selection contexts. These rents may provide operator with an incentive to capture the decision-maker to manipulate his decision so that bundling is always chosen. Information rents are the engines of any capture of such a decision-maker.

Of course, for this story to hold, two extra ingredients are needed. First, the decisionmaker must be non-benevolent and attracted by the prospects of withdrawing private benefits from conceding favors to the operator. Second, the decision-maker and the operator must share some piece of private information which is not available to the general public and this piece of information must give some rent to the operator.

In our context, this piece of information from which the decision-maker gets discretion is the sign of the externality between the two tasks. By hiding evidences on a negative externality that would optimally call for unbundling, the decision-maker may let the operator enjoy some extra information rent associated with an inefficient choice of bundling. Preventing such manipulation has a social cost which must be taken into account at the time of evaluating whether bundling is the most preferred organizational form from a social welfare point of view.

To make the political economy model described below more transparent, we depart from the ownership considerations discussed in Section 6 completely. As argued above, ownership problems arise in incomplete contracting environments, but this incompleteness is not really needed in order to understand the stake of the operator in manipulating the public decision on whether to bundle or not. What really matters is the link between the information rent of the operator and the organizational structure.

To extend the scope of our previous model to a political economy context, let us suppose that the level of the externality $\tilde{\delta}$ is a random variable taking values in $\{\bar{\delta},-\bar{\delta}\}$ (where $\bar{\delta}>0$ ) with respective probabilities $\nu$ and $1-\nu$. We assume that $\tilde{\delta}$ is a piece of information learnt by both the decision-maker and the operator. They may collude to hide this piece of information from the general public.

Let us also assume that the mean $\eta_{0}$ of the shock $\tilde{\eta}$ on operating costs is also a random variable taking values in $\left\{\underline{\eta}_{0}, \bar{\eta}_{0}\right\}$ with respective probabilities $p$ and $1-p$ (with $\Delta \eta_{0}=\bar{\eta}_{0}-\underline{\eta}_{0}>0$ ). The operator with type $\underline{\eta}_{0}$ is on average more efficient. $\eta_{0}$ is realized after $\delta$ has been learned by the decision-maker and the operator. This is the operator's private information on $\eta_{0}$ which gives him an information rent.

Benevolent Decision-Maker. Suppose first that the decision-maker is benevolent and reveals truthfully any information he may have on $\delta$ so that the best organizational form

\footnotetext{
${ }^{37}$ The operator's ex ante participation constraint is always binding.
} 
is always chosen.

In this environment with asymmetric information on $\eta_{0}$, an incentive mechanism is a menu $\left\{\alpha\left(\hat{\eta}_{0}\right), \beta\left(\hat{\eta}_{0}\right), a\left(\hat{\eta}_{0}\right), b\left(\hat{\eta}_{0}\right)\right\}$ (resp. $\left.\left\{\alpha\left(\hat{\eta}_{0}\right), a\left(\hat{\eta}_{0}\right), B\left(\hat{\eta}_{0}\right)\right\}\right)$ under unbundling (resp. bundling) where $\hat{\eta}_{0}$ is the operator's report on $\eta_{0}$. According to the Revelation Principle, ${ }^{38}$ there is no loss of generality in focusing on such truthful mechanisms. Once the operator has picked the contract corresponding to his type $\eta_{0}$, effort levels are chosen according to the organizational structure which prevails.

Unbundling. When the operator reports $\hat{\eta}_{0}$, he chooses an effort $e_{2}=\alpha\left(\hat{\eta}_{0}\right)$ whereas the builder chooses $e_{1}=a\left(\hat{\eta}_{0}\right)$. The certainty equivalent of the operator's expected utility is:

$$
\hat{U}_{\mathcal{O}}\left(\eta_{0}, \hat{\eta}_{0}\right)=\beta\left(\hat{\eta}_{0}\right)-\alpha\left(\hat{\eta}_{0}\right)\left(\eta_{0}-\alpha\left(\hat{\eta}_{0}\right)-\delta a\left(\hat{\eta}_{0}\right)\right)-\frac{\left(1+r \sigma_{\varepsilon}^{2}\right)}{2} \alpha^{2}\left(\hat{\eta}_{0}\right) .
$$

Denoting $\hat{U}_{\mathcal{O}}\left(\eta_{0}, \eta_{0}\right)=U_{\mathcal{O}}\left(\eta_{0}\right)$, the relevant adverse selection incentive constraint of a low-cost operator can be written as:

$$
U_{\mathcal{O}}\left(\underline{\eta}_{0}\right) \geq U_{\mathcal{O}}\left(\bar{\eta}_{0}\right)+\alpha\left(\bar{\eta}_{0}\right) \Delta \eta_{0},
$$

whereas the participation constraint of a high-cost operator is:

$$
U_{\mathcal{O}}\left(\bar{\eta}_{0}\right) \geq 0
$$

These are the only binding constraints at the optimum. ${ }^{39}$ We show in the Appendix that the socially optimal mechanism implements the same effort level for an efficient operator than when $\underline{\eta}_{0}$ is common knowledge. Only the power of the inefficient operator's incentive scheme diminishes to reduce the the adverse selection information rent of a $\underline{\eta}_{0}$ operator:

$$
\begin{gathered}
a^{u}\left(\underline{\eta}_{0}, \delta\right)=a^{u}\left(\bar{\eta}_{0}, \delta\right)=e_{1}^{u}, \\
\alpha^{u}\left(\underline{\eta}_{0}, \delta\right)=e_{2}^{u}>\alpha^{u}\left(\bar{\eta}_{0}, \delta\right)=\frac{1-\frac{p}{1-p} \Delta \eta_{0}}{1+r \sigma_{\eta}^{2}} .
\end{gathered}
$$

In the sequel we shall assume that $1>\frac{p}{\nu(1-p)} \Delta \eta_{0}$ to maintain a positive effort by both types of operators even under adverse selection and the threat of capture. We also make explicit the dependence of the solution on $\delta$ when needed.

Finally, note that the builder's incentive scheme is not distorted because it plays no role in reducing the operator's rent. It thus induces the same quality-enhancing effort as in Section 3.

Bundling. The merged entity $\mathcal{B}-\mathcal{O}$ now internalizes the impact of his quality-enhancing effort on cutting operational costs. $\mathcal{B}-\mathcal{O}$ chooses effort levels on both tasks, which are, respectively, given by $e_{2}=\alpha\left(\hat{\eta}_{0}\right)$ and $e_{1}=a\left(\hat{\eta}_{0}\right)-\delta \alpha\left(\hat{\eta}_{0}\right)$, when he reports having realized average costs $\hat{\eta}_{0}$. $\mathcal{B}-\mathcal{O}$ gets thus a certainty equivalent of his expected utility which is

\footnotetext{
${ }^{38}$ See Laffont and Martimort (2002, Chapter 2).

${ }^{39}$ This is a standard result of two-type adverse selection models. See Laffont and Martimort (2002, Chapter 2), for instance.
} 
worth:

$$
\begin{aligned}
\hat{U}_{\mathcal{B}-\mathcal{O}}\left(\eta_{0}, \hat{\eta}_{0}\right) & =B\left(\hat{\eta}_{0}\right)-\alpha\left(\hat{\eta}_{0}\right)\left(\eta_{0}-\alpha\left(\hat{\eta}_{0}\right)-\delta\left(a\left(\hat{\eta}_{0}\right)-\delta \alpha\left(\hat{\eta}_{0}\right)\right)\right) \\
& +a\left(\hat{\eta}_{0}\right)\left(a\left(\hat{\eta}_{0}\right)-\delta \alpha\left(\hat{\eta}_{0}\right)\right)-\frac{\left(1+r \sigma_{\eta}^{2}\right)}{2} \alpha^{2}\left(\hat{\eta}_{0}\right)-\frac{\left(1+r \sigma_{\varepsilon}^{2}\right)}{2}\left(a\left(\hat{\eta}_{0}\right)-\delta \alpha\left(\hat{\eta}_{0}\right)\right)^{2} .
\end{aligned}
$$

Denoting the merged entity's information rent by $U_{\mathcal{B}-\mathcal{O}}\left(\eta_{0}\right)=\hat{U}_{\mathcal{B}-\mathcal{O}}\left(\eta_{0}, \hat{\eta}_{0}\right)$, the relevant incentive compatibility and participation constraints are still (10) and (11). Both constraints are, again, binding at the social optimum and, again, only the bonus $\alpha\left(\bar{\eta}_{0}\right)$ is used to extract the costly information rent of the $\underline{\eta}_{0}$-operator. This leads to the solution:

$$
\begin{gathered}
a^{b}\left(\underline{\eta}_{0}, \delta\right)=e_{1}^{b}>a^{b}\left(\bar{\eta}_{0}, \delta\right) \Leftrightarrow \delta>0, \\
\alpha^{b}\left(\underline{\eta}_{0}, \delta\right)=e_{2}^{b}>\alpha^{b}\left(\bar{\eta}_{0}, \delta\right) .
\end{gathered}
$$

As previously, reducing the information rent of the efficient operator calls for moving the cost-reimbursement rule towards a cost-plus contract. Depending on the sign of the externality, this has also a negative impact on the merged entity's incentives for enhancing the quality of the infrastructure. When $\delta>0$, having more of a cost-plus contract on operations also reduces these incentives, whereas the reverse happens with $\delta<0$.

Gathering the results of the optimization both with respect to bundling and unbundling, we observe that the only role of adverse selection is to diminish the social benefit of inducing a cost-reducing effort by the inefficient operator. Instead of being equal to 1 , as before, this social benefit must be reduced in order to take into account of the socially costly information rent left to the most efficient operator. The corresponding virtual social benefit becomes $1-\frac{p}{1-p} \Delta \eta_{0}$. These distortions are thus independent of the sign of the externality. Since the optimal organizational choice does not depend on the social benefits of both tasks, but only on the sign of $\delta$, we can directly import the results of Proposition 1.

Proposition 9. Assume that the operator has private information on his average costs $\eta_{0}$ and that the decision-maker is benevolent. Then, the optimal organizational form is still bundling (resp. unbundling) when $\delta>0$ (resp. $\delta<0)$.

Asymmetric information on $\eta_{0}$ per se is not enough to modify the basic insights of Section 3 when the decision-maker is benevolent. A positive externality still calls for bundling.

Non-Benevolent Decision-Maker. Suppose now that the decision-maker is non-benevolent and may be captured by the privately informed operator who withdraws some information rent. This decision-maker is thus now viewed as a strategic player with his own private incentives. In particular, he must be induced to reveal to the public the realized value of $\tilde{\delta}$.

Let us suppose that a negative externality may be manipulated and publicly reported as being a positive one. In contrast, the reverse manipulation is assumed to be not feasible. ${ }^{40}$

\footnotetext{
${ }^{40}$ The information structure is thus such that $\tilde{\delta}$ is partially verifiable in the sense of Green and Laffont (1986).
} 
When the decision-maker hides the realized negative externality $-\bar{\delta}$ from the general public and reports instead a positive externality $\bar{\delta}$, the decision of whether to separate the two tasks is unduly modified into a decision of whether to bundle them. Through this modification, the operator increases then his expected information rent by an amount:

$$
p \Delta \eta_{0}\left(\alpha^{b}\left(\bar{\eta}_{0}, \bar{\delta}\right)-\alpha^{u}\left(\bar{\eta}_{0},-\bar{\delta}\right)\right)
$$

This quantity represents the stake of capture. It is in fact positive when evaluated at the optimal incentive schemes found above. Indeed, it is proportional to the difference in the efforts made by an inefficient operator between the cases of bundling and unbundling, namely $e_{2}^{b}-e_{2}^{u}$, and this quantity is positive at $\bar{\delta}$ as one can see from Proposition 1 .

We will assume that the non-benevolent decision-maker has all of the bargaining power in the collusive side-deal with the operator. Before the operator knows $\eta_{0}$, the decisionmaker makes thus a take-it-or-leave-it offer, asking for a bribe equal to $p \Delta \eta_{0}\left[\alpha^{b}\left(\bar{\eta}_{0}, \bar{\delta}\right)-\right.$ $\left.\alpha^{u}\left(\bar{\eta}_{0},-\bar{\delta}\right)\right]$ and, in exchange, commits to report $\hat{\delta}=\bar{\delta}$ when instead $\delta=-\bar{\delta}$.

Following Tirole (1986), the decision-maker enjoys an ex ante private benefit from his possible collusion with the operator which is worth:

$$
k(1-\nu) p \Delta \eta_{0} \max \left\{\left(\alpha^{b}\left(\bar{\eta}_{0}, \bar{\delta}\right)-\alpha^{u}\left(\bar{\eta}_{0},-\bar{\delta}\right)\right), 0\right\} .
$$

The fraction $1-k$ represents the deadweight-loss of capture associated to the fact that sidedeals are unofficial side-contracts which are enforced only by repetition, 'words of honor', etc., or which entail non-monetary transfers between the colluding partners. Preventing capture of the decision-maker is socially costly. To behave, the decision-maker should actually receive at least his expected benefit from manipulating information. (16) is thus an extra agency cost that must be paid by society to prevent capture. This agency cost is reduced by distorting downward $\alpha^{b}\left(\bar{\eta}_{0}, \bar{\delta}\right)$ and by increasing $\alpha^{u}\left(\bar{\eta}_{0},-\bar{\delta}\right)$. This stake fully disappears if $\alpha^{b}\left(\bar{\eta}_{0}, \bar{\delta}\right)$ is equal to $\alpha^{u}\left(\bar{\eta}_{0},-\bar{\delta}\right)$.

Keeping as fixed the decision rule to bundle tasks when $\delta>0$ and to split them when $\delta<0$, one may investigate how the threat of capture changes incentives. Note first that one may always choose $\alpha^{b}\left(\bar{\eta}_{0}, \bar{\delta}\right)=\alpha^{u}\left(\bar{\eta}_{0},-\bar{\delta}\right)$. With such a policy, the decision-maker has no longer any discretion over tailoring the power of the operator's incentives to the sign of the externality. The stake of capture disappears even though one may still benefit from a positive externality under bundling in state $\bar{\delta}$ in order to boost the effort on the first task.

Proposition 10. There exists $\bar{\delta}_{0}>0$ such that for $\bar{\delta}<\bar{\delta}_{0}$ capture is never a concern but the cost reimbursement rule does not depend on $\delta: \alpha^{b}\left(\bar{\eta}_{0}, \bar{\delta}\right)=\alpha^{u}\left(\bar{\eta}_{0},-\bar{\delta}\right)$. More generally, $\alpha^{b}\left(\bar{\eta}_{0}, \bar{\delta}\right)\left(\right.$ resp. $\left.\alpha^{u}\left(\bar{\eta}_{0},-\bar{\delta}\right)\right)$ is reduced (resp. increased) under the threat of capture.

The possibility to manipulate the sign of the externality gives discretionary power to the decision-maker. When the externality is negative, he might instead reveal to the public that it is positive thereby leading to bundling whereas splitting tasks would have been optimal. To avoid this issue, cost-reimbursement rules must be tilted towards costplus contracts under bundling and towards fixed-price contracts under unbundling. This means that efforts will be somewhat misallocated under both organizational forms with little internalization of the positive externality under bundling. This convergence of costreimbursement rules might go up to the point where they are the same, irrespective of the 
organizational form. Then the collusive stake fully disappears, but much of the benefits of bundling are lost in the process.

\section{Conclusion}

The presence of a production externality between building and operating assets raises the issue of the optimal organization of such tasks. Bundling allows to better internalize this externality and improves incentives when the externality is positive, thereby increasing welfare. In contrast, when the externality is negative, unbundling reduces agency costs and is socially preferable. Hence, a simple and technology-driven reason is at the heart of the decision to bundle or unbundle the various activities. This result is obtained under a class of restricted schemes where the compensation of an agent depends only on his own performances, but it holds more generally with a larger class of compensations, whether the decision-maker relies on a single agent or on a consortium to perform both tasks and even under asymmetric information and the risk of capture. In each case, we showed how the basic lessons of our framework should be modified and, in particular, the directions towards which cost-reimbursement rules should be distorted to account for various contractual environments.

Even though this organizational issue seems a priori somewhat orthogonal to the ownership issue which has often been pushed forward in the PPP literature, it helps to understand part of the debate about it. To the extent that ownership of an infrastructure is a very crude contract, but sometimes the only feasible one, leaving ownership to the builder might be the only device to provide incentives to building and designing it efficiently. The discrete contractual choice of whether to leave ownership does not allow to fine tune incentives as efficiently as under more complete contracts. Nevertheless, the insights obtained in our more complete contracts framework might at least partly carry over. Depending on the private benefits that the builder withdraws from ownership and the risks he bears when acquiring assets, public-private partnerships- defined as the joint bundling of tasks and allocation of ownership to the builder- might nevertheless outperform the more traditional form of public procurement (where a local government keeps ownership of the assets and chooses two different contractors at each stage) in the case of a positive externality. The reverse may happen for a negative externality. Of course, all the extensions investigated in this paper could also be possibly cast in an incomplete contracts setting. We feel reasonably confident that the results found in more complete contracting environments would carry over at least to some extent, but, certainly, some more formal analysis is required to qualify this assertion.

Coming back to our initial complete contracting framework, several other extensions seem to us particularly attractive. First, it could be worth coming back to the maintained assumption that the firms' degree of risk-aversion was kept constant as one changes organizational modes. Section 5 has gone some way towards endogenizing that degree but certainly more could be done. More specifically, one may be interested in tracing out the impact of organizational forms (whether firms are multi-taskers or not) on their access to the financial market and thus on the amount of risk they should keep as a result of frictions on these markets. The corporate finance literature (see Leland and Pyle (1977), for instance) suggests reasons (related most notably to asymmetric information and frictions 
in getting access to the capital markets) why firms may not be able to fully diversify. In a full-fledged model one might want to analyze how the decision whether to bundle activities affects these frictions on the capital market. The implicit assumption that we maintained here was that these frictions remain by and large independent of the chosen organizational form but the validity of this assumption should be further investigated.

Second, in our modelling of consortia between builders and operators, we have assumed that efforts of the member firms could be coordinated efficiently. This assumption should be relaxed. Consortia may be inefficient when they suffer from internal agency problems. These problems may tilt the organizational choice towards unbundling. In an incomplete contracts perspective this would make a stronger the case for the more traditional form of procurement.

Third, our approach of the political economy of PPPs has been very partial in stressing only one aspects of it: the possibility of excessive manipulations by decision-makers to favor the formation of large conglomerates. We show that a robust form of procurement immune to the risk of capture goes towards low-powered incentives and cost-reimbursement rules that might not really help firms to internalize the gains from bundling. This is clearly reminiscent of a move towards traditional forms of procurement. The extent to which the choice of procurement modes responds to political forces remains nevertheless by large to be investigated.

Finally, it could be worth investigating whether competition between potential builders and between operators may also change the incentives to form consortia and the decision of whether to bundle activities. 


\section{Appendix}

\section{A.1 Proof of Proposition 1}

Given a linear restricted incentive scheme, the builder wants to maximize the certaintyequivalent of his expected utility, namely:

$$
b+a e_{1}-\psi\left(e_{1}\right)-\frac{r \sigma_{\varepsilon}^{2}}{2} a^{2} .
$$

The builder's effort is thus given by (2). The fixed-fee $b$ chosen by the government extracts all the builder's expected profit:

$$
b=\frac{e_{1}^{2}}{2}\left(r \sigma_{\varepsilon}^{2}-1\right) .
$$

Similar computations can be made for the operator who wants to maximize:

$$
\beta-\alpha\left(\eta_{0}-e_{2}-\delta e_{1}\right)-\psi\left(e_{2}\right)-\frac{r \sigma_{\eta}^{2}}{2} \alpha^{2}
$$

and chooses an effort level given by again by (2). The optimal fixed-fee which extracts all the operator's expected profit is:

$$
\beta=e_{2} \eta_{0}+\frac{e_{2}^{2}}{2}\left(r \sigma_{\eta}^{2}-1\right)-\delta e_{1} e_{2} .
$$

Taking into account the expression of these fixed-fees, the local government optimizes under unbundling the following expression of expected social welfare:

$$
\left(P^{u}\right): \max _{\left(e_{1}, e_{2}\right) \in \mathbb{R}_{+}^{2}} W^{u}\left(e_{1}, e_{2}, \delta\right) \equiv(S+\delta) e_{1}+e_{2}-\frac{e_{1}^{2}}{2}\left(1+r \sigma_{\varepsilon}^{2}\right)-\frac{e_{2}^{2}}{2}\left(1+r \sigma_{\eta}^{2}\right) .
$$

This leads to the agents' effort levels given by (3).

Under bundling the merger gets an expected payoff worth:

$$
B-\alpha\left(\eta_{0}-e_{2}-\delta e_{1}\right)+a e_{1}-\psi\left(e_{1}\right)-\psi\left(e_{2}\right)-\frac{r \sigma_{\varepsilon}^{2}}{2} a^{2}-\frac{r \sigma_{\eta}^{2}}{2} \alpha^{2}
$$

where the effort levels are given by (4). The fixed-fee $B$ is then used by the principal to extract $\mathcal{B}-\mathcal{O}$ 's expected rent so that the government's problem can be written as:

$$
\left(P^{b}\right): \max _{\left(e_{1}, e_{2}\right) \in \mathbb{R}_{+}^{2}} W^{b}\left(e_{1}, e_{2}, \delta\right) \equiv(S+\delta) e_{1}+e_{2}-\frac{e_{1}^{2}}{2}-\frac{r \sigma_{\varepsilon}^{2}}{2}\left(e_{1}-\delta e_{2}\right)^{2}-\frac{e_{2}^{2}}{2}\left(1+r \sigma_{\eta}^{2}\right),
$$

the optimum $\left\{e_{1}^{b}, e_{2}^{b}\right\}$ of which is given by: ${ }^{41}$

$$
e_{1}^{b}=\frac{(S+\delta)\left(1+r \sigma_{\eta}^{2}+\delta^{2} r \sigma_{\varepsilon}^{2}\right)+\delta r \sigma_{\varepsilon}^{2}}{\left(1+r \sigma_{\eta}^{2}\right)\left(1+r \sigma_{\varepsilon}^{2}\right)+\delta^{2} r \sigma_{\varepsilon}^{2}} \text { and } e_{2}^{b}=\frac{1+r \sigma_{\varepsilon}^{2}+(S+\delta) \delta r \sigma_{\varepsilon}^{2}}{\left(1+r \sigma_{\eta}^{2}\right)\left(1+r \sigma_{\varepsilon}^{2}\right)+\delta^{2} r \sigma_{\varepsilon}^{2}}
$$

To keep the analysis interesting, we will assume that $e_{k}^{b} \geq 0$ (for $k \in\{1,2\}$ ) which neces-

\footnotetext{
${ }^{41}$ The second-order conditions are trivially satisfied.
} 
sarily holds when $\delta>0$ (positive externality), but also when $\delta<0$ but small compared with $S$ (the case of a sufficiently weak negative externality).

Remember now that agents get no expected profit in each configuration. Moreover, looking at $W^{u}\left(e_{1}, e_{2}, \delta\right)$ and $W^{b}\left(e_{1}, e_{2}, \delta\right)$, the welfare comparison between the bundling and the unbundling scenarios only depends on the comparison of effort levels. Simple manipulations show that:

$$
e_{1}^{b}-e_{1}^{u} \propto \delta\left[1+r\left(1+\delta^{2}+\delta S\right) \sigma_{\varepsilon}^{2}\right], \text { and } e_{2}^{b}-e_{2}^{u} \propto \delta\left[S+r(S+\delta) \sigma_{\eta}^{2}\right] .
$$

The proposition follows.

\section{A.2 Proof of Proposition 2}

Under unbundling and general schemes the builder maximizes:

$$
\max _{e_{1} \in \mathbb{R}_{+}} b+a e_{1}-a^{\prime}\left(\eta_{0}-e_{2}-\delta e_{1}\right)-\psi\left(e_{1}\right)-\frac{r}{2}\left(a^{2} \sigma_{\varepsilon}^{2}+a^{\prime 2} \sigma_{\eta}^{2}\right) .
$$

The builder's effort is now given by (5). As usual by now, the principal sets the fixed-fee so as to extract all the builder's expected rent, i.e.:

$$
b=\frac{r}{2}\left[\sigma_{\varepsilon}^{2}\left(e_{1}-a^{\prime} \delta\right)^{2}+\sigma_{\eta}^{2} a^{\prime 2}\right]-e_{1}\left(\frac{e_{1}}{2}-a^{\prime} \delta\right)+a^{\prime}\left(\eta_{0}-e_{2}-\delta e_{1}\right) .
$$

Expected welfare under unbundling can thus be written as:

$$
W^{u}\left(e_{1}, e_{2}, a^{\prime}, \delta\right)=(S+\delta) e_{1}+e_{2}-\frac{e_{1}^{2}}{2}-\frac{e_{2}^{2}}{2}-\frac{r \sigma_{\eta}^{2}}{2} e_{2}^{2}-\frac{r}{2}\left[\left(e_{1}-\delta a^{\prime}\right)^{2} \sigma_{\varepsilon}^{2}+a^{\prime 2} \sigma_{\eta}^{2}\right] .
$$

To better understand the comparison between organizational forms, it may be useful to optimize first over the piece-rate parameter $a^{\prime}$ and, from there, get an indirect welfare function $\tilde{W}^{u}\left(e_{1}, e_{2}, \delta\right)$ which depends only on the effort variables $\left(e_{1}, e_{2}\right)$. Doing so yields (6) and a new expression of the principal's maximization problem as: ${ }^{42}$

$$
\max _{\left(e_{1}, e_{2}\right) \in \mathbb{R}_{+}^{2}} \tilde{W}^{u}\left(e_{1}, e_{2}, \delta\right)=(S+\delta) e_{1}+e_{2}-\frac{e_{1}^{2}}{2}-\frac{e_{2}^{2}}{2}-\frac{r \sigma_{\eta}^{2}}{2} e_{2}^{2}-\frac{r \sigma_{\varepsilon}^{2} \sigma_{\eta}^{2}}{2\left(\sigma_{\eta}^{2}+\delta^{2} \sigma_{\varepsilon}^{2}\right)} e_{1}^{2} .
$$

Solving for the first-order conditions associated with the three free parameters $e_{1}, e_{2}$ and $a^{\prime}$, the optimal effort levels under unbundling are given by:

$$
e_{1}^{u}=\frac{(S+\delta)\left(\delta^{2} \sigma_{\varepsilon}^{2}+\sigma_{\eta}^{2}\right)}{\sigma_{\eta}^{2}+\sigma_{\varepsilon}^{2}\left(\delta^{2}+r \sigma_{\eta}^{2}\right)}, e_{2}^{u}=\frac{1}{1+r \sigma_{\eta}^{2}}
$$

The optimal piece-rate parameters are denoted by $\alpha^{u}, a^{\prime} u$, and $a^{u}$.

Let us now turn to the case of bundling. Remember that expected welfare under bundling is given by (A4). Comparing (A8) and (A4) is then straightforward, at least in the limit of a small positive externality. The gain from bundling is of a first-order

\footnotetext{
${ }^{42}$ We also have: $\frac{\partial^{2} \tilde{W}^{u}}{\partial e_{1}^{2}}=-\left(1+r \sigma_{\varepsilon}^{2}\right), \frac{\partial^{2} \tilde{W}^{u}}{\partial e_{2}^{2}}=-\left(1+r \sigma_{\eta}^{2}\right), \frac{\partial^{2} \tilde{W}^{u}}{\partial a^{\prime 2}}=-r\left(\delta^{2} \sigma_{\varepsilon}^{2}+\sigma_{\eta}^{2}\right), \frac{\partial^{2} \tilde{W}^{u}}{\partial e_{1} \partial e_{2}}=0, \frac{\partial^{2} \tilde{W}^{u}}{\partial e_{2} \partial a^{\prime}}=0$, $\frac{\partial^{2} \tilde{W}^{u}}{\partial e_{1} \partial a^{\prime}}=-\delta r \sigma_{\varepsilon}^{2}$. One can then check that the Hessian associated to the maximization problem is negative semi-definite at the optimum.
} 
magnitude in $\delta$ since now a merged entity can better internalize the choice of qualityenhancing and cost-reducing efforts. Tedious, but straightforward, computations show that:

$$
\begin{gathered}
\lim _{\delta \rightarrow 0} W^{b}\left(e_{1}^{b}, e_{2}^{b}\right)-W^{u}\left(e_{1}^{u}, e_{2}^{u}, a^{\prime u}\right)=0, \\
\lim _{\delta \rightarrow 0} \frac{d}{d \delta}\left[W^{b}\left(e_{1}^{b}, e_{2}^{b}\right)-W^{u}\left(e_{1}^{u}, e_{2}^{u}, a^{\prime u}\right)\right]=\frac{r S \sigma_{\varepsilon}^{2}}{\left(1+r \sigma_{\varepsilon}^{2}\right)\left(1+r \sigma_{\eta}^{2}\right)}>0 .
\end{gathered}
$$

\section{A.3 Proof of Proposition 3}

$\mathcal{J V}$ maximizes the certainty equivalent of the aggregate payoff of the firms subject to constraints $a_{\mathcal{B}}+a_{\mathcal{O}}=a$ and $\alpha_{\mathcal{B}}+\alpha_{\mathcal{O}}=\alpha$ which captures the fact that the aggregate compensation risk is shared between these firms. $\mathcal{J} \mathcal{V}$ 's problem can thus be written as:

$\max _{\left\{a_{\mathcal{B}}, \alpha_{\mathcal{B}},\left(e_{1}, e_{2}\right) \in \mathbb{R}_{+}^{2}\right\}} B+a e_{1}-\alpha\left(\eta_{0}-e_{2}-\delta e_{1}\right)-\frac{e_{1}^{2}}{2}-\frac{e_{2}^{2}}{2}-\frac{r \sigma_{\varepsilon}^{2}}{2}\left[\left(a-a_{\mathcal{B}}\right)^{2}+a_{\mathcal{B}}^{2}\right]-\frac{r \sigma_{\eta}^{2}}{2}\left[\left(\alpha-\alpha_{\mathcal{B}}\right)^{2}+\alpha_{\mathcal{B}}^{2}\right]$.

Because both firms have the same risk tolerance, they share equally the risk of the aggregate compensation:

$$
a_{\mathcal{B}}=a_{\mathcal{O}}=\frac{a}{2} \text { and } \alpha_{\mathcal{B}}=\alpha_{\mathcal{O}}=\frac{\alpha}{2} .
$$

For a given incentive scheme offered by the government, optimal effort levels are thus the same as in Section 3:

$$
e_{1}=a+\delta \alpha \text { and } e_{2}=\alpha \text {. }
$$

The government's problem becomes thus:

$$
\max _{\left(e_{1}, e_{2}\right) \in \mathbb{R}_{+}^{2}} W^{c}\left(e_{1}, e_{2}, \delta\right)=(S+\delta) e_{1}+e_{2}-\frac{e_{1}^{2}}{2}-\frac{r \sigma_{\varepsilon}^{2}}{4}\left(e_{1}-\delta e_{2}\right)^{2}-\frac{e_{2}^{2}}{2}\left(1+\frac{r \sigma_{\eta}^{2}}{2}\right) .
$$

Using (A5), but for a level of risk-aversion half as high, the optimal effort levels with an efficient consortium are now given by:

$$
e_{1}^{c}=\frac{(S+\delta)\left(1+\frac{r \sigma_{\eta}^{2}}{2}+\frac{\delta^{2} r \sigma_{\varepsilon}^{2}}{2}\right)+\frac{\delta r \sigma_{\varepsilon}^{2}}{2}}{\left(1+\frac{r \sigma_{\eta}^{2}}{2}\right)\left(1+\frac{r \sigma_{\varepsilon}^{2}}{2}\right)+\frac{\delta^{2} r \sigma_{\varepsilon}^{2}}{2}} \text { and } e_{2}^{c}=\frac{1+\frac{r \sigma_{\varepsilon}^{2}}{2}+(S+\delta) \frac{\delta r \sigma_{\varepsilon}^{2}}{2}}{\left(1+\frac{r \sigma_{\eta}^{2}}{2}\right)\left(1+\frac{r \sigma_{\varepsilon}^{2}}{2}\right)+\frac{\delta^{2} r \sigma_{\varepsilon}^{2}}{2}}
$$

The comparison of (A3) and (A9) is now straightforward.

\section{A.4 Proof of Proposition 4}

Immediate.

\section{A.5 Proof of Proposition 5}

Following from the discussion in the text, social welfare under unbundling can be written as:

$$
W_{G}^{u}\left(e_{2}\right)=e_{2}-\frac{e_{2}^{2}}{2}\left(1+r \sigma_{\eta}^{2}\right),
$$

where $e_{2}$ is the operator's cost-reducing effort. 
Since the merged entity bears no risk linked to the realized quality of the infrastructure when it is not the owner, social welfare can be written as:

$$
W_{G}^{b}\left(e_{2}, \delta\right)=\left\{\delta(S+\delta) e_{2}-\frac{\delta^{2} e_{2}^{2}}{2}\right\}+\left\{e_{2}-\frac{e_{2}^{2}}{2}\left(1+r \sigma_{\eta}^{2}\right)\right\} .
$$

Denoting $e_{2 G}^{b}$ as the optimal effort, we have:

$$
e_{2 G}^{b}=\frac{1+\delta(S+\delta)}{1+r \sigma_{\eta}^{2}+\delta^{2}}
$$

The first bracketed term is the social value of the quality-enhancing effort when the incentives for doing so come only from the willingness of the merged entity to reduce his operating cost. Assuming that $\delta$ is small enough, this is a positive term when evaluated at the effort level $e_{2}^{u}=1 /\left(1+r \sigma_{\eta}^{2}\right)$ which maximizes (A10). The second bracketed term is nothing else than the expression for $W_{G}^{u}\left(e_{2}\right)$. Henceforth, we get the result.

\section{A.6 Proof of Proposition 6}

Under unbundling, the builder's payoff as an owner is:

$$
-\mathbb{E}_{(\tilde{\varepsilon}, \tilde{\eta})}\left(\exp \left(-r\left(P\left(e_{1}+\tilde{\varepsilon}\right)-\frac{e_{1}^{2}}{2}-b\right)\right),\right.
$$

whose certainty equivalent is worth:

$$
P e_{1}-\frac{r \sigma_{\varepsilon}^{2}}{2} P^{2}-\frac{e_{1}^{2}}{2}-b,
$$

where (8) holds and $b$ is a fixed-fee paid by the builder to become an owner.

Social welfare under unbundling expressed again as a function of the operator's effort can be written as:

$$
\begin{aligned}
W_{B}^{u}\left(e_{2}, \delta\right) & =\mathbb{E}\left[(S-P)\left(e_{1}+\tilde{\varepsilon}\right)-\left(\tilde{\eta}-e_{2}-\delta e_{1}\right)+b-\beta+\alpha\left(\tilde{\eta}-e_{2}-\delta e_{1}\right)\right], \\
& =(S+\delta) P-\frac{P^{2}}{2}\left(1+r \sigma_{\varepsilon}^{2}\right)+e_{2}-\frac{e_{2}^{2}}{2}\left(1+r \sigma_{\eta}^{2}\right),
\end{aligned}
$$

since, because he is not the owner, the principal enjoys only $E \times \tilde{q}$ from the infrastructure building. Of course, this expression is still maximized for $e_{2}^{u}$.

Under bundling, the agent's payoff as an owner is:

$$
-\mathbb{E}_{(\tilde{\varepsilon}, \tilde{\eta})}\left[\exp \left(-r\left(P\left(e_{1}+\tilde{\varepsilon}\right)-\frac{e_{1}^{2}}{2}+\beta-\alpha\left(\tilde{\eta}-e_{2}-\delta e_{1}\right)-\frac{e_{2}^{2}}{2}\right)\right)\right],
$$

whose certainty equivalent is worth:

$$
P e_{1}-\frac{r \sigma_{\varepsilon}^{2}}{2} P^{2}-\frac{e_{1}^{2}}{2}+\beta-\alpha\left(\eta_{0}-e_{2}-\delta e_{1}\right)-\frac{e_{2}^{2}}{2}-\frac{r \sigma_{\eta}^{2}}{2} \alpha^{2},
$$

where $e_{1}$ and $e_{2}$ satisfy (9). 
The principal's expected payoff wan be written as:

$$
\mathbb{E}_{(\tilde{\varepsilon}, \tilde{\eta})}\left(E\left(e_{1}+\tilde{\varepsilon}\right)-\beta-(1-\alpha)\left(\tilde{\eta}-e_{2}-\delta e_{1}\right)\right) .
$$

Note that when the fixed-fee $\beta$ is used to extract all the builder's expected payoff, social welfare becomes:

$$
W_{B}^{b}\left(e_{2}, \delta\right)=(S+\delta) e_{1}+e_{2}-\frac{r \sigma_{\varepsilon}^{2}}{2} P^{2}-\frac{e_{1}^{2}}{2}-\left(1+r \sigma_{\eta}^{2}\right) \frac{e_{2}^{2}}{2} .
$$

Or using (9) to eliminate $e_{1}$ :

$$
W_{B}^{b}\left(e_{2}, \delta\right)=(S+\delta)\left(P+\delta e_{2}\right)-\frac{r \sigma_{\varepsilon}^{2}}{2} P^{2}-\frac{1}{2}\left(P+\delta e_{2}\right)^{2}+e_{2}-\frac{e_{2}^{2}}{2}\left(1+r \sigma_{\eta}^{2}\right) .
$$

Denoting $e_{2 B}^{b}$ as the corresponding optimal effort, we have:

$$
e_{2 B}^{b}=\frac{1+\delta(S+\delta-P)}{1+r \sigma_{\eta}^{2}+\delta^{2}} .
$$

Simple manipulations show that:

$$
W_{B}^{b}\left(e_{2}, \delta\right)-W_{B}^{u}\left(e_{2}, \delta\right)=\delta e_{2}\left(S+\delta-\frac{\delta}{2} e_{2}-P\right)
$$

which is positive at $e_{2}^{u}$ when $P \leq S+\delta-\frac{\delta}{2} e_{2}^{u}$, i.e., $P$ is small enough.

\section{A.7 Proof of Proposition 7}

We observe that:

$$
W_{B}^{b}\left(e_{2}, \delta\right)-W_{G}^{b}\left(e_{2}, \delta\right)=P\left(S+\delta-\delta e_{2}-\frac{1}{2}\left(1+r \sigma_{\varepsilon}^{2}\right) P\right)
$$

which is positive at $e_{2 G}^{b}$ when $P$ is small enough.

\section{A.8 Proof of Proposition 8}

We observe that:

$$
W_{B}^{u}\left(e_{2}, \delta\right)-W_{G}^{u}\left(e_{2}, \delta\right)=(S+\delta) P-\frac{\left(1+r \sigma_{\varepsilon}^{2}\right)}{2} P^{2}
$$

which is negative when $P>\frac{2(S+\delta)}{1+r \sigma_{\varepsilon}^{2}}$. Hence, government ownership is better than private ownership under unbundling. Moreover, using (A13), we observe also that when $\delta<0$ :

$$
\begin{aligned}
W_{B}^{b}\left(e_{2}, \delta\right)-W_{G}^{u}\left(e_{2}, \delta\right) & =(S+\delta) P-\frac{\left(1+r \sigma_{\varepsilon}^{2}\right)}{2} P^{2}+\delta(S+\delta) e_{2}-\frac{\delta^{2} e_{2}^{2}}{2}-\delta P e_{2} \\
& <P\left(S+\delta-\frac{\left(1+r \sigma_{\varepsilon}^{2}\right)}{2} P-\delta e_{2}\right)
\end{aligned}
$$


which is a negative number at $e_{2 B}^{b}$ when $P>\frac{2\left(S+\delta-\delta e_{2 B}^{b}\right)}{1+r \sigma_{\varepsilon}^{2}}>\frac{2(S+\delta)}{1+r \sigma_{\varepsilon}^{2}}$. Since $P<S$, a necessary condition to have this last inequality, at least in the case where $\delta$ is large enough, is that $\sigma_{\varepsilon}^{2}$ is large enough.

Therefore, government ownership and unbundling dominates builder ownership whether bundling or unbundling has been chosen. Note that these lower bounds on $P$ are more likely to hold when $\sigma_{\varepsilon}^{2}$ or $|\delta|$ increases.

\section{A.9 Proof of Proposition 9}

Taking into account the binding incentive and participation constraints, the socially optimal contract under unbundling when the realized externality is $\delta$ solves the reduced-form problem:

$$
\max _{\{\alpha(\cdot), a(\cdot)\}} p\left[W^{u}\left(a\left(\underline{\eta}_{0}\right), \alpha\left(\underline{\eta}_{0}\right), \delta\right)-\alpha\left(\bar{\eta}_{0}\right) \Delta \eta_{0}\right]+(1-p) W^{u}\left(a\left(\bar{\eta}_{0}\right), \alpha\left(\bar{\eta}_{0}\right), \delta\right) .
$$

The optimization is straightforward and yields (12) and (13).

Similarly, the optimal contract under bundling solves:

$$
\max _{\{\alpha(\cdot), a(\cdot)\}} p\left[W^{b}\left(a\left(\underline{\eta}_{0}\right), \alpha\left(\underline{\eta}_{0}\right), \delta\right)-\alpha\left(\bar{\eta}_{0}\right) \Delta \eta_{0}\right]+(1-p) W^{b}\left(a\left(\bar{\eta}_{0}\right), \alpha\left(\bar{\eta}_{0}\right), \delta\right) .
$$

which leads to

$$
\begin{gathered}
a^{b}\left(\underline{\eta}_{0}, \delta\right)=e_{1}^{b}>a^{b}\left(\bar{\eta}_{0}, \delta\right)=\frac{(S+\delta)\left(1+r \sigma_{\eta}^{2}+\delta^{2} r \sigma_{\varepsilon}^{2}\right)+\delta r \sigma_{\varepsilon}^{2}\left(1-\frac{p}{1-p} \Delta \eta_{0}\right)}{\left(1+r \sigma_{\eta}^{2}\right)\left(1+r \sigma_{\varepsilon}^{2}\right)+\delta^{2} r \sigma_{\varepsilon}^{2}} \Leftrightarrow \delta>0, \\
\alpha^{b}\left(\underline{\eta}_{0}, \delta\right)=e_{2}^{b}>\alpha^{b}\left(\bar{\eta}_{0}, \delta\right)=\frac{\left(1+r \sigma_{\varepsilon}^{2}\right)\left(1-\frac{p}{1-p} \Delta \eta_{0}\right)+(S+\delta) \delta r \sigma_{\varepsilon}^{2}}{\left(1+r \sigma_{\eta}^{2}\right)\left(1+r \sigma_{\varepsilon}^{2}\right)+\delta^{2} r \sigma_{\varepsilon}^{2}}
\end{gathered}
$$

\section{A.10 Proof of Proposition 10}

Taking into account that bundling (resp. unbundling) is implemented when $\delta>0$ (resp. $\delta<0$ ), expected social welfare can thus be written as:

$$
\begin{gathered}
\nu\left\{p\left(W^{b}\left(a^{b}\left(\underline{\eta}_{0}, \bar{\delta}\right)-\delta \alpha^{b}\left(\underline{\eta}_{0}, \bar{\delta}\right), \alpha^{b}\left(\underline{\eta}_{0}, \bar{\delta}\right), \bar{\delta}\right)-\alpha^{b}\left(\bar{\eta}_{0}, \bar{\delta}\right) \Delta \eta_{0}\right)+(1-p) W^{b}\left(a^{b}\left(\bar{\eta}_{0}, \bar{\delta}\right)-\delta \alpha^{b}\left(\bar{\eta}_{0}, \bar{\delta}\right), \alpha^{b}\left(\bar{\eta}_{0}, \bar{\delta}\right), \bar{\delta}\right)\right\} \\
+(1-\nu)\left\{p\left(W^{u}\left(a^{u}\left(\underline{\eta}_{0}, \bar{\delta}\right), \alpha^{u}\left(\underline{\eta}_{0},-\bar{\delta}\right),-\bar{\delta}\right)-\alpha^{u}\left(\bar{\eta}_{0},-\bar{\delta}\right) \Delta \eta_{0}\right)+(1-p) W^{u}\left(a^{u}\left(\bar{\eta}_{0},-\bar{\delta}\right), \alpha^{u}\left(\bar{\eta}_{0},-\bar{\delta}\right),-\bar{\delta}\right)\right\} \\
-k(1-\nu) p \Delta \eta_{0} \max \left\{0 ; \alpha^{b}\left(\bar{\eta}_{0}, \bar{\delta}\right)-\alpha^{u}\left(\bar{\eta}_{0},-\bar{\delta}\right)\right\} .
\end{gathered}
$$

Let us first consider the case where the optimal bonuses $\tilde{\alpha}^{b}\left(\bar{\eta}_{0}, \bar{\delta}\right)$ and $\tilde{\alpha}^{u}\left(\bar{\eta}_{0},-\bar{\delta}\right)$ under the threat of capture are such that $\tilde{\alpha}^{b}\left(\bar{\eta}_{0}, \bar{\delta}\right)>\tilde{\alpha}^{u}(\bar{\eta},-\bar{\delta})$ so that there is a positive stake of capture. Optimizing yields:

$$
\tilde{\alpha}^{b}\left(\bar{\eta}_{0}, \bar{\delta}\right)=\frac{\left(1+r \sigma_{\varepsilon}^{2}\right)\left(1-\frac{p}{1-p} \Delta \eta_{0}\left(1+k\left(\frac{1-\nu}{\nu}\right)\right)\right)+(S+\bar{\delta}) \bar{\delta} r \sigma_{\varepsilon}^{2}}{\left(1+r \sigma_{\eta}^{2}\right)\left(1+r \sigma_{\varepsilon}^{2}\right)+\bar{\delta}^{2} r \sigma_{\varepsilon}^{2}}<\alpha^{b}\left(\bar{\eta}_{0}, \bar{\delta}\right),
$$


and:

$$
\tilde{\alpha}^{u}\left(\bar{\eta}_{0},-\bar{\delta}\right)=\frac{1-\frac{p}{1-p} \Delta \eta_{0}(1-k)}{1+r \sigma_{\eta}^{2}}>\alpha^{u}\left(\bar{\eta}_{0},-\bar{\delta}\right) .
$$

This is really the optimum when $\tilde{\alpha}^{b}\left(\bar{\eta}_{0}, \bar{\delta}\right)>\tilde{\alpha}^{u}\left(\bar{\eta}_{0},-\bar{\delta}\right)$, i.e., when there is a positive stake of capture. Let us suppose that:

$$
1>\frac{p}{1-p} \Delta \eta_{0}\left(1+\frac{k(1-\nu)}{\nu}\right)
$$

so that $\tilde{\alpha}^{b}\left(\bar{\eta}_{0}, \bar{\delta}\right)$ is a positive number for sure. Then, note that as $\bar{\delta}$ is small enough:

$$
\tilde{\alpha}^{b}\left(\bar{\eta}_{0}, \bar{\delta}\right) \underset{\bar{\delta} \rightarrow 0}{\sim} \frac{1-\frac{p}{1-p} \Delta \eta_{0}\left(1+\frac{k(1-\nu)}{\nu}\right)}{1+r \sigma_{\eta}^{2}}<\tilde{\alpha}^{u}\left(\bar{\eta}_{0},-\bar{\delta}\right) .
$$

Thus for $\bar{\delta}$ small enough, we have $\tilde{\alpha}^{b}\left(\bar{\eta}_{0}, \bar{\delta}\right)<\tilde{\alpha}^{u}\left(\bar{\eta}_{0},-\bar{\delta}\right)$ and a contradiction. This is more likely as $k$ increases. For $\bar{\delta}$ small enough, the optimum is achieved when $\tilde{\alpha}^{b}\left(\bar{\eta}_{0}, \bar{\delta}\right)=$ $\tilde{\alpha}^{u}\left(\bar{\eta}_{0},-\bar{\delta}\right)$.

\section{References}

Baron, D. \& Besanko, D. (1992). "Information, Control and Organizational Structure." Journal of Economics and Management Strategy, 1: 237-275.

Baron, D. \& Besanko, D. (1999). "Informational Alliance." Review of Economic Studies, 66: 743-768.

Bennett, J. \& Iossa, E. (2002). "Building and Managing Facilities for Public Services." Mimeo Brunel University.

Berger, R. (1985). "Private Sector Initiatives in the Reagan Era: New Actors Rework on Old Theme?" In L. Salomon and M. Lund (Eds.), The Reagan Presidency and the Governing of America (pp. 181-211). The Urban Institute Press, Washington D.S.

Che, Y.K. \& Yoo, S.W. (2001). "Optimal Incentives for Teams." American Economic Review, 91: 525-541.

Choi, Y.K. (1993). "Managerial Incentive Contracts with a Production Externality." Economics Letters, 42: 37-42.

Dana, J. (1993). "The Organization and Scope of Agents: Regulating Multiproduct Industries." Journal of Economic Theory, 59: 288-310.

Daniels, R. \& Trebilcock, M. (2002). "An Organizational Analysis of the Public-Private Partnership in the Provision of Public Infrastructure." In P. Vaillancourt Rosenau (Ed.), Public-Private Policy Partnerships. MIT Press, Cambridge.

Dequiedt, V. \& Martimort, D. (2004). "Delegated Monitoring versus Arm's Length Contracting." International Journal of Industrial Organization, 22: 951-981. 
Gilbert, R. \& Riordan, M. (1995). "Regulating Complementary Products : A Comparative Institutional Analysis." Rand Journal of Economics, 26: 243-256.

Green, J. \& Laffont, J.-J. (1986). "Partially Verifiable Information and Mechanism Design." Review of Economic Studies, 53: 447-456.

Grossman, S. \& Hart, O. (1986). "The Costs and Benefits of Ownership: A Theory of Vertical and Lateral Integration." Journal of Political Economy, 94: 691-719.

Hart, O. (2003). "Incomplete Contracts and Public Ownership: Remarks and an Application to Public-Private Partnership." Economic Journal, 113: 69-76.

Hart, O., Shleifer, A. \& Vishny, R., (1997). "The Proper Scope of Government: Theory and Applications to Prisons." Quarterly Journal of Economics, 112: 1119-1158.

Holmström, B. (1979). "Moral Hazard and Observability." The Bell Journal of Economics, 10: 74-91.

Holmström, B. \& Milgrom, P., (1987). "Aggregation and Linearity in the Provision of Intertemporal Incentives." Econometrica, 55: 303-328.

Holmström, B. \& Milgrom, P. (1990). "Regulating Trade among Agents." Journal of Institutional and Theoretical Economics, 146: 85-105.

Holmström, B. \& Milgrom, P. (1991). "Multitask Principal-Agent Analyses: Incentive Contracts, Asset Ownership and Job Design." Journal of Law, Economics and Organization, 7: 24-52.

Itoh, H. (1993). "Coalitions, Incentives and Risk-Sharing." Journal of Economic Theory, 60: 410-427.

Itoh, H. (1994). "Cooperation in Hierarchical Organizations: An Incentive Perspective." Journal of Law, Economics and Organization, 60: 410-427.

Laffont, J.-J. \& Martimort, D. (1998). "Collusion and Delegation." Rand Journal of Economics, 29: 280-305.

Laffont, J.-J. \& Martimort, D. (2002). The Theory of Incentives: The PrincipalAgent Model. Princeton University Press.

Laffont, J.-J. \& Tirole, J. (1993). A Theory of Incentives in Regulation and Procurement. MIT Press, Cambridge.

Leland, H. \& Pyle, D. (1977). "Informational Asymmetries, Financial Structure and Financial Intermediation." Journal of Finance, 32: 371-387.

Macho-Stadler, I. \& Perez-Castrillo, D. (1993). "Moral Hazard with Several Agents: The Gains from Cooperation." International Journal of Industrial Organization, 11: 73-100.

Mc Afee, P. \& Mc Millan, J. (1995). "Organizational Diseconomies of Scope." Journal of Economics and Management Strategy, 4: 399-426. 
Mookherjee, D. \& Tsumagari, M. (2004). "The Organization of Supplier Networks: Effects of Delegation and Intermediation." Econometrica, 72: 11791219 .

Ramakrishnan, R. \& Thakor, A. (1991). "Cooperation versus Competition in Agency." Journal of Law, Economics and Organization, 7: 248-283.

Schmitz, P. (2005). "Allocating Control in Agency Problems with Limited Liability and Sequential Hidden Actions." CEPR Discussion Papers 5145.

Schneider, A. L. (2000). "Public-Private Partnerships in the U.S. Prison System." In P. Vaillancourt Rosenau (Ed). Public-private policy partnerships, MIT Press, Cambridge Mass. and London.

Tirole, J. (1986). "Hierarchies and Bureaucracies: on the Role of Collusion in Organizations." Journal of Law, Economics and Organization, 2: 181-214.

Varian, H. (1989). "Monitoring Agents with Other Agents." Working Paper 89-18, U. Michigan, Center for Research on Economic and Social Theory.

Wilson, R. (1968). "The Theory of Syndicates." Econometrica, 36: 119-132. 